\title{
O professor e qualidade de ensino: uma análise a partir dos resultados do Saeb na escola pública do Paraná
}

\author{
Teacher and teaching quality: an analysis based on the \\ results of Saeb in public school of Paraná state, Brazil
}

\section{Simoni Vilant de Biasi ${ }^{1}$}

\section{Resumo:}

Este trabalho, resultado da minha pesquisa de mestrado 2 em Políticas e Gestão da Educação, toma como ponto de partida que há necessidade de educação de qualidade para todos, como condição de formação humana, e que esta se dá por meio da transmissão dos conhecimentos e dos elementos culturais considerados básicos para a vida social. Para identificar fatores relacionados aos docentes que apresentam impacto no atendimento dessa necessidade, realizou-se uma análise das relações que se estabelecem entre as condições de formação e de trabalho dos professores de 8. ' série da escola pública do Paraná com a proficiência estudantil. Assim, a investigação lançou um olhar sobre as condições docentes e analisou como estas se constituem em peças importantes na construção da qualidade de ensino. Para a análise dessas relações foram utilizadas as informações apresentadas pelo Sistema Nacional de Avaliação da Educação Básica (SAEB) de 2003. A pesquisa apontou a necessidade de políticas públicas de formação e de trabalho para os docentes como condição prioritária para a realização da qualidade do ensino.

Palavras chave: qualidade de ensino; condições docentes e proficiência escolar

\begin{abstract}
:
This article, which is the result of my master's research about Policies and Management of Education, takes as its main point that it's necessary a quality education for everybody, as a condition of human education, and that this occurs through the transmission of cultural elements regarded as fundamental to social life. In order to identify the factors related to teachers, which could contribute to satisfy that condition, we examine here how the conditions of formation and of work of teachers of 8th stage in public schools of Paraná are related to proficiency of students. So, this investigation is concerned about the conditions of teaching and examines their importance for the construction of quality of teaching. The analysis is based on informations presented by National System of Evaluating Basic Education (SAEB) 2003, and shows that public policies of formation and of work for teachers are the most important condition for quality of teaching.
\end{abstract}

Keywords: quality of teaching; formation of teacher; conditions of teaching work 


\section{Introdução}

O debate sobre o problema da falta de qualidade no ensino brasileiro tem travado discussões sobre quais elementos e quais condições se associariam para determinar a superação desta baixa qualidade. Porém, há um obstáculo que invariavelmente aflora nessas discussões, a inexistência de um conceito unívoco sobre o que afinal seja o ensino de qualidade. Essa dificuldade está ligada às várias interpretações que a locução ensino de qualidade enseja, tendo em vista que uma ou outra interpretação oscila em função dos valores políticos e ideológicos que estão associados às representações e aos interesses que os sujeitos têm sobre o que tem valor no mundo social.

Acresce que, como ensina Vitor Paro, quando os objetivos que se pretendem buscar com a educação não são suficientemente explicitados e justificados pode acontecer a não correspondência entre medidas proclamadas e resultados obtidos (PARO, 2001, p. 33).

Para acompanhar a qualidade da educação brasileira, a partir da década de 1990, o sistema educacional brasileiro passou a contar com um - Sistema de Avaliação da Educação Básica (SAEB). O SAEB é composto por dois processos: a Avaliação Nacional da Educação Básica (ANEB) - que recebe o nome de SAEB - e a Avaliação Nacional do Rendimento Escolar (ANRESC) que recebe o nome de Prova Brasil (MEC, 2008).

As avaliações do SAEB produzem informações a respeito da realidade educacional brasileira - as classifica por regiões, redes de ensino pública e privada nos estados e no Distrito Federal - por meio de exame bienal de proficiência, em Matemática e em Língua Portuguesa (leitura), aplicado em amostras de alunos de $4 .^{a}$ e $8 .^{a}$ séries do ensino fundamental e da 3 . $^{a}$ série do ensino médio.

Além de coletar dados sobre a qualidade da educação no País, o SAEB procura identificar as condições internas e externas que interferem no processo de ensino e aprendizagem, por meio da aplicação de questionários de contexto respondidos por alunos, professores e diretores, e por meio da coleta de informações sobre as condições físicas da escola e dos recursos que ela dispõe (MEC, 2008).
O Ministério da Educação e Cultura (MEC) afirma que, por meio do levantamento dos dados dessa avaliação são instituídas medidas contextuais, além das de aprendizagem, que permitem indicar quais fatores da escola, de sua gestão e dos seus docentes contribuem para a construção da qualidade da escola pública brasileira (MEC, 2006).

É importante ressaltar que este artigo, que resulta de uma pesquisa de mestrado, insere-se na discussão acerca das condições relacionadas ao professor e no que essas interferem na qualidade do ensino. A problemática que moveu a pesquisa foi saber quais são as condições de formação e de trabalho dos professores da 8. ${ }^{a}$ série do Paraná e como essas condições interferem na qualidade de ensino.

Todavia, a hipótese que sustentou a pesquisa é a de que a qualidade do ensino depende da qualidade, dentre outros, dos elementos que constituem a profissão docente e por isso, questões acerca das condições de formação e de trabalho precisam ser identificadas para definir um padrão de qualidade.

A análise dos resultados desses instrumentos buscou apresentar indicações do efeito destes fatores sobre o desempenho dos alunos. Sobre os professores, O SAEB oferece informações que incluem as variáveis sobre sexo e idade, formação e experiência profissional (tempo de trabalho na área da educação e regência de classe, escolarização e capacitação), situação funcional (situação trabalhista, salarial e de carga horária), prática docente (planejamento, livro didático e opinião sobre a aprendizagem dos alunos) e organização e favorabilidade do ambiente da escola (participação dos professores na gestão escolar e opinião sobre as condições de trabalho). Para o Ministério, mediante o resultado da proficiência dos alunos é possível avaliar as condições que se associam e indicam a qualidade do ensino (MEC, 2006).

No que se refere à seleção de questões do questionário respondido pelos professores, foram selecionadas aquelas referentes às políticas públicas docentes, por estas estarem diretamente ligadas à qualidade e à política pública de ensino. 
No quadro abaixo, seguem as questões selecionadas referentes à formação e condições de trabalho com os fatores explicativos de cada âmbito:

\section{QUADRO 1- QUESTÕES SELECIONADAS}

\begin{tabular}{|c|c|c|}
\hline \multicolumn{3}{|c|}{ Fatores explicativos } \\
\hline 욤 & Escolarização & Nível máximo de escolarização. \\
\hline 옹 & Capacitação & $\begin{array}{l}\text { Participa de atividade de formação } \\
\text { continuada. }\end{array}$ \\
\hline 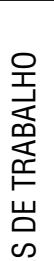 & $\begin{array}{l}\text { Experiência } \\
\text { Profissional }\end{array}$ & $\begin{array}{c}\text { Anos de trabalho no magistério; } \\
\text { Anos de trabalho na mesma escola; } \\
\text { Tempo de regência na mesma turma; } \\
\text { Número de escolas que trabalha; } \\
\text { Quantas horas-aula ministra } \\
\text { por semana. }\end{array}$ \\
\hline 柋 & $\begin{array}{l}\text { Situação } \\
\text { funcional }\end{array}$ & $\begin{array}{c}\text { Situação trabalhista na escola; } \\
\text { Salário bruto como professor. } \\
\text { Situação Funcional }\end{array}$ \\
\hline
\end{tabular}

FONTE: MEC/INEP/SAEB DE 2003

Para o cruzamento das informações dos professores com a média dos alunos na prova do SAEB, o modelo de análise usado na pesquisa organizou a média da proficiência (cada aluno foi testado em apenas uma disciplina) da turma, agrupada com o professor da disciplina, por meio de tabelas. Assim, obteve-se um modelo de análise das variáveis, no qual se articula a média da proficiência dos alunos com as características dos professores, a fim de verificar a interferência ou não da formação e das condições dos docentes no desempenho escolar desses alunos.

A variável tomada dos dados dos alunos foi a média obtida pelo conjunto aluno na prova de língua portuguesa e de matemática que é organizada por escala crescente, da nota menor para a nota maior. Essa nota é interpretada pelas competências e habilidades que os alunos devem desempenhar nas séries frequentadas, definindo o que é saber para uma criança de 11 anos e/ou um jovem de 14. Por exemplo, a nota em leitura de um aluno na prova é classificada em oito níveis. Este grande número de níveis é usado simplesmente porque a escala usada para registrar a nota dos alunos de quarta série é a mesma utilizada para alunos de oitava série. Com isso, espera-se, naturalmente, que alunos da $4 .^{a}$ série tenham notas menores e estejam situados em níveis mais baixos. No entanto, é preciso estabelecer claramente acima de qual desses níveis um aluno deve estar quando domina a competência leitora de forma adequada. Assim, define-se que os alunos da quarta série devam alcançar média acima de 200 pontos e os de oitava série acima de 275. Esses parâmetros foram reformulados e adotados a partir do Plano de Desenvolvimento da Educação (PDE), do Ministério da Educação (MEC, 2008).

A utilização homogênea do escore da turma e não do rendimento nas provas individuais dos alunos se deu pela necessidade de relacionar as médias com os dados referentes à formação e às condições dos professores das disciplinas pesquisadas.

A escolha dos professores da $8 .^{a}$ série, das escolas públicas do Estado do Paraná, definiu-se pela exigência de qualificação em nível superior nas áreas específicas de conhecimento (Art. 62 da LDB/9.394/96).

O número de elementos da amostra foi de 142 professores e 1.920 alunos: 959 alunos de língua portuguesa e 961 alunos de matemática, que correspondem ao conjunto dos alunos e professores de $8 .^{a}$ série do Estado do Paraná, avaliados pelo SAEB de 2003, que, por sua vez, consistem nos dados disponíveis referentes àquele ano no período de realização da pesquisa.

A organização dos dados corresponde à divisão feita por quartis do conjunto da amostra. A pesquisa analisou os professores que tiveram seus alunos classificados no $1 .^{\circ}$ quartil $-25 \%$ do total dos resultados situados no extremo inferior e no $4 .^{\circ}$ quartil $-25 \%$ dos resultados situados no extremo superior.

Considerando que a escala desejada para os alunos de 8 . $^{a}$ série é de 275 pontos, verificou-se que as médias apresentadas pelos alunos do Estado do Paraná foram baixas, o que expressa deficiência na qualidade de ensino das escolas do Paraná. As notas variam numa escala de 178,61 a 289,25 em língua portuguesa e de 210,70 a 312,46 em matemática. 
É fato que, nos últimos anos, as políticas públicas - influenciadas por organismos multilaterais - trouxeram ao centro de suas preocupações um modelo de desenvolvimento profissional dos professores tendo em vista a melhoria na qualidade do ensino. Como também é inquestionável que o professor é peça fundamental na conquista dessa qualidade e que o nível de qualidade docente é, também, determinado pela qualidade das condições a partir das quais a profissão se realiza.

\section{As condições docentes e a qualidade do ensino na escola pública do Paraná}

Devemos lutar pela igualdade sempre que a diferença nos inferioriza, mas devemos lutar pela diferença sempre que a igualdade nos descaracteriza.

Boaventura de Souza Santos

As palavras em epígrafe, de Boaventura de Souza Santos, sinalizam para o grande desafio posto à escola pública. A luta pela igualdade no acesso à escola fundamental por parte de populações historicamente excluídas já foi quase totalmente vencida. Agora a luta se constitui em torno da superação da diferença nos resultados estudantis, qual seja, fazer com que os alunos que ingressam na escola em condições desiguais sejam tratados de modo diferente para que a qualidade dos resultados seja a mesma para todos. Isto é, seja realizada a dimensão democratizadora do direito à educação.

Por isso, conforme autores como Dubet, 2004; Soares \& Marotta, 2009, tratar todos igualmente num sistema escolar desigual, em uma sociedade desigual, oferecendo oportunidades formais a todos os alunos, colabora para que os mais privilegiados tenham maiores chances de ter um melhor desempenho e possibilidades de ascender a uma educação de qualidade e a uma inserção social mais efetiva.

As análises realizadas, a partir dos dados da avaliação oficial - SAEB- acerca do princípio constitucional (art. 206, inciso VII da Constituição Federal) e da garantia na LDB (art. $4 .^{\circ}$, inciso IX) de padrão mínimo de qualidade do ensino, dão respostas de que a mesma não se efetivou. Essa realidade pode ser constatada nos dados do SAEB/2003 do estado do Paraná, pois esses informam que há diferenças significativas entre os resultados da proficiência. As notas, como se viu, variam numa escala de 178,61 a 289,25 em língua portuguesa e de 210,70 a 312,46 em matemática.

Os resultados estudantis verificados no Estado do Paraná indicam uma realidade não igualitária, a partir da qual se pode afirmar que o direito à educação - com padrões mínimos, tendo a igualdade como princípio fundante da qualidade, conforme previsto na CF (Constituição Federal) de 1988 - não se efetivou, ou seja, o mínimo ainda não foi garantido.

Sobre a garantia de padrões mínimos de qualidade, a reflexão de Dubet (2004, p. 546) contribui no sentido de entender que:

Uma das formas de justiça social consiste em garantir um mínimo de recursos e proteção aos mais fracos e desfavorecidos. Desse ponto de vista, um sistema justo garantiria limites mínimos abaixo dos quais ninguém deveria ficar: é o caso do salário mínimo, da assistência médica, dos benefícios elementares que protegem os mais fracos da exclusão total. Na verdade, essas garantias visam a limitar os efeitos dos sistemas meritocráticos cuja mecânica muitas vezes leva à manutenção ou mesmo acentuação das desigualdades.

Com isso, o que fica claro é que a declaração do direito estabelecido no texto constituinte criou condições para a expansão do acesso à escola nestes últimos anos, mas que é necessário alcançar outras dimensões para a efetivação e legitimação desse direito, como a garantia de um padrão de qualidade definido pelas condições materiais e humanas que interferem no ensino.

Mesmo assim, não podemos ignorar que essa igualdade de acesso supõe, na contramão da escola, uma grande redução das desigualdades sociais; nenhuma escola pode sozinha, criar uma sociedade mais igualitária (DUBET, 2004).

Para que os alunos das classes populares realizem mais plenamente seus estudos, será necessário que tenham condições materiais 
adequadas, professores bem formados, com boas condições de trabalho, infra-estrutura na escola e materiais didáticos adequados; para que todos aprendam a ler, será preciso maior tempo de aprendizagem nas escolas; para que os alunos tenham acesso à cultura, urge organizar clubes de teatro e cinema para aqueles que têm apenas uma televisão em casa ou nem tanto.

Cabe, então, criar as condições de efetivação do princípio constitucional ${ }^{3}$ do padrão de qualidade do ensino como nova dimensão do direito à educação (ARAÚJO \& OLIVEIRA, 2003).

Para a garantia de padrões de qualidade, incluindo a igualdade ao acesso e à permanência na escola, é necessário oferecer condições escolares que são fundamentais para a construção de uma educação de qualidade. Pois, uma educação de qualidade é resultado das condições objetivas ofertadas aos sujeitos envolvidos na ação pedagógica do processo educativo. Portanto, a educação escolar se concretiza mediante as condições objetivas de todos os sujeitos que dela participam.

Dessa forma, falar em educação de qualidade abrange os aspectos e os meios que determinarão a sua qualidade, que incluem principalmente os alunos - os sujeitos que precisam aprender - e os professores - os sujeitos que ensinam, que são os responsáveis diretos pelo processo propriamente dito. Quando o professor tem as condições objetivas para mobilizar o processo, no caso o aprendizado do aluno, cresce a possibilidade de realizar uma educação de qualidade. Nesse sentido, qualificar suas condições de atuação é um dos desafios maiores apresentado ao sistema educacional.

Como mediador do processo educativo, o professor atinge o padrão de qualidade necessário para tal, por meio de boas condições de formação e de trabalho. Para tanto, é importante que se garanta formação inicial e continuada aos profissionais e também outras condições, tais como: estabilidade do corpo docente, tempo para estudos e realização do trabalho coletivo, uma adequada relação entre o número de professores e o número de alunos, carreira e salários condizentes com a importância do trabalho.

É fato notório que no nosso país existe insatisfação por parte dos professores com as atuais estruturas salariais, carreiras profissionais e condições de trabalho, bem como é notório os efeitos desse processo na qualidade da educação. Este artigo, que é resultado de uma pesquisa de mestrado que estudou o fator professor e sua relação com os resultados estudantis, aponta problemas ligados à formação, à carreira e ao salário.

Essas variáveis mostraram influência no alcance da qualidade do ensino. Verificouse que existe uma relação complexa entre as condições de qualidade do desempenho profissional com o resultado do processo educativo (BIASI, 2009).

A pesquisa realizada permitiu identificar as seguintes questões relevantes, em se tratando do perfil do professor de $8{ }^{a}$ série e a sua relação com a qualidade do ensino.

\section{Formação inicial}

Em síntese, os dados apontam que a habilitação necessária exigida pela legislação específica, para todos os profissionais que atuam nos anos finais da educação básica, não foi universalizada e o sistema escolar convive ainda com a inclusão de professores leigos. $O$ problema da qualidade do ensino, em parte, pode estar atrelado à falta de profissionais habilitados nas áreas que lecionam, pois, 18,7\% (Ensino Médio e Ensino Superior - Outros) dos professores tiveram alunos com o índice de proficiência menor que a média esperada no exame do SAEB. Confrontando a exigência da formação com o desempenho dos alunos, viuse que dos professores $(38,6 \%)$ licenciados em 
matemática, 56,3\% tiveram uma interferência positiva sobre desempenho dos alunos da 8. ${ }^{a}$ série. Porém, provavelmente por outros fatores, esta informação se mostra contrária em relação aos professores licenciados em letras. Os professores $(42,9 \%)$ licenciados em Letras tiveram mais alunos com resultados $(55,6 \%)$ abaixo da média.

\section{Formação continuada}

Dentre os pesquisados, $73 \%$ dos professores paranaenses afirmaram ter participado de alguma atividade de formação continuada. Esse percentual indica que a exigência legal (LDB art. 62) não está sendo cumprida totalmente pelos sistemas. Mas, como a pergunta é vaga e pouco especificada, não se pode avaliar o seu impacto no desempenho dos alunos. Professores com formação continuada estão distribuídos de modo equivalente entre os alunos dos dois níveis de desempenho avaliados. Nos $25 \%$ dos alunos com desempenho maior que o da média, tem-se $75,8 \%$ de professores que declararam ter participado nos últimos anos em alguma atividade de formação continuada. Esse percentual é quase idêntico entre os alunos com desempenho abaixo da média, no caso $74,3 \%$. $62 \%$ dos professores responderam que a formação continuada foi útil na sua prática, porém esses mesmos professores tiveram 65,5\% dos alunos abaixo da média.

\section{Tempo de serviço}

Os dados mostram que os professores com mais tempo de serviço tiveram maior interferência positiva sobre o desempenho dos alunos.

De fato, percebeu-se que à medida que aumenta o tempo de docência aumenta a concentração de resultados positivos de proficiência. Os melhores resultados correspondem ao maior tempo de docência, pois dos alunos dos professores com tempo de docência de 15 a 20 anos, 27,3\%, obtiveram colocação no mais alto quartil, maior percentual de alunos nesta faixa, e dos alunos de professores com mais de 20 anos, 24,2\% obtiveram colocação neste mesmo quartil.
A pesquisa mostrou que o tempo de serviço dos professores na mesma escola varia entre menos de 1 ano (18,3\%), de 1 a 2 anos $(15,5 \%), 3$ a 5 anos $(21,1 \%)$, de 6 a 9 anos $(23,9 \%)$ de 10 a 15 anos (12\%), de 15 a 20 anos (8,5\%) e mais de 20 anos (0,7\%). Quanto à interferência do tempo de serviço na mesma escola, os dados mostraram que trabalhar de 6 a 9 anos e de 10 a 15 anos, na mesma escola produziu um efeito positivo sobre o desempenho dos alunos, $21,2 \%$ e $18,2 \%$ dos alunos que obtiveram desempenho acima da média tem professores de 6 a 9 anos e de 10 a 15 anos na mesma escola, respectivamente. Esses resultados confirmam a necessidade de estabilidade e lotação do professor em uma mesma unidade escolar.

\section{Salário}

No quesito salário, o SAEB 2003 indicou que a maioria dos docentes da $8 .^{a}$ série no Paraná, tinha uma média salarial entre quatro e seis salários mínimos, esses professores somavam um percentual de $42,3 \%$. Verificando a interferência destes no desempenho dos estudantes, percebe-se que os alunos desses professores obtiveram resultados equivalentes, ou seja, 39,4\% alcançaram o primeiro quartil e $41,7 \%$ ficaram no último quartil, portanto, houve equilíbrio entre o número desses professores e o resultado dos alunos. Já, entre os professores pesquisados que ganham entre 1 e 2 salários, nenhum está com aluno que tenha obtido o nível mais alto dos quartis. Em contrapartida, dos professores que ganham de 6 a 9 salários, mesmo sendo eles apenas $23,2 \%$ do total de professores, $33,3 \%$ de seus alunos obtiveram grau de proficiência no mais alto quartil.

Os dados do SAEB também permitiram informar a média salarial dos professores cruzando a carga horária com a formação. Como critério, os professores foram classificados por carga de trabalho semanal, de 30 a 40 horas. Com essa carga horária de trabalho, preponderou a média salarial de 4 a 6 salários $(53,9 \%)$ e, em segundo a média 
de 6 a 9 salários (22,5\%). Relacionando o salário com a formação, os professores com magistério de nível médio ganham em torno de 2 a 4 salários, enquanto a maioria dos professores com licenciatura ganha em torno de 4 a 6 salários. Desta forma, constata-se que a formação impacta nas condições salariais dos professores e, por sua vez, essas condições nos resultados escolares.

\section{Carreira}

Os dados da pesquisa mostram que as escolas públicas do Paraná tinham apenas 56,3\% de professores estatutários. São professores concursados que têm cargos efetivos na rede de ensino. Verificou-se também a existência de $26,8 \%$ em regime CLT, 13,4\% como prestadores de serviço por contrato temporário e 3,5\% com outros vínculos. Nesse contexto, 43,7\% dos professores que trabalham com alunos de escolas públicas tem empregos precários, o que é um percentual alarmante. Comparando a situação funcional com os resultados, 66,7\% dos professores com estabilidade funcional estatutária estão com os alunos que tiveram melhores desempenhos. Se comparado com as outras situações funcionais, verifica-se um movimento inverso: $41,7 \%$ dos celetistas, $11,1 \%$ dos contratados temporários e 5,6\% dos que tem vínculo por meio de outros contratos estão entre os alunos que ficaram com o desempenho abaixo da média. Também se verificou que os professores que têm vínculo estatutário são os que têm salários melhores. A maioria dos professores que ganha de 6 a 9 salários e de 9 a 12 salários são estatutários e a maioria dos celetistas ganha em média de 2 a 4 salários. Esses resultados confirmam a importância de um plano de carreira para a qualidade do ensino e indicam a urgência para superação dos contratos precários e instáveis.

\section{Conclusão}

A análise realizada, a partir dos dados do SAEB de 2003, indica a necessidade de implantação e complementação das políticas públicas de profissionalização e de valorização do professor no que se refere à formação inicial e continuada; plano de cargo, carreira e salário e garantia de condições de trabalho, conforme já estabelecido legalmente. Porém, a inexistência de um padrão claro de condições, a resistência dos mantenedores e os problemas de financiamento dificultam tal encaminhamento.

Uma escola de qualidade se efetiva mediante um quadro de profissionais qualificados e compromissados com a aprendizagem dos alunos. A definição do que seja um ensino de boa ou de má qualidade passa pela relação direta entre a boa formação dos profissionais e adequadas condições de trabalho e o melhor desempenho dos alunos, ou seja, a qualificação docente e as condições de trabalho devem ser vistas como variáveis importantes no processo de efetivação do bom desempenho dos estudantes e, consequentemente, o efetivo alcance da qualidade.

Em relação ao trabalho do professor, destacase também a garantia de horário específico na jornada de trabalho para outras atividades, além daquelas dedicadas às atividades de ensino em sala. Esse tempo favorece o estudo individualizado, a integração entre os docentes, o trabalho coletivo, o planejamento de estudos, o atendimento de alunos e pais, enfim, a consecução dos objetivos da escola na ação pedagógica dos mesmos.

Outro elemento importante, relacionado aos resultados escolares, considerado positivo para aprendizagem dos alunos, é a lotação dos professores, por meio de concurso público em somente uma escola; uma vez que esse fator permite que os docentes conheçam melhor e se dediquem mais plenamente às necessidades da escola, dos alunos e da comunidade escolar.

Em síntese, a efetivação de políticas de profissionalização e de valorização da profissão docente se constitui em estratégia principal na busca da educação de qualidade. Essas políticas permitemestabelecer umpadrão qualitativo no que tange ao perfil docente: titulação e qualificação adequada ao exercício profissional; vínculo efetivo de trabalho; dedicação a uma só escola; formas de ingresso e condições de trabalho adequadas; valorização da experiência docente; 
progressão na carreira por meio da qualificação permanente e outros requisitos. Tais expectativas baseiam-se na lógica da qualidade, decorrente da qualificação dos processos educativos para o alcance do produto educacional desejado.

Mesmo que os dados sejam limitados quanto às informações qualitativas acerca do professor, pode-se dizer que eles confirmam a situação de desqualificação e de desvalorização na qual os professores se encontram. As informações produzidas pela avaliação, mesmo com alcance reduzido, são importantes instrumentos para avaliação das políticas educacionais e para a própria escola avaliar com todos os sujeitos envolvidos na sua prática. Os professores também devem avaliar os resultados da sua ação, mas, para isso, precisam ter condições de trabalho que o permitam.

A pesquisa também mostrou que o principal problema da avaliação externa reside na forma como os dados são analisados, lidos e interpretados, e do ponto de vista social e pedagógico adotado, o qual pode reduzir sua complexidade a uma mera classificação e culpabilização do professor.

A avaliação só tem sentido, se tem o objetivo e a finalidade de melhorar a qualidade do ensino. Portanto, não vale a pena só avaliar e descrever os resultados, o avaliador deve ter interesse em melhorar aquilo que não atende aos objetivos propostos para então tomar decisões que levem à melhoria dos resultados.

$\mathrm{Na}$ perspectiva da mera descrição, a avaliação pode se transformar em instrumento de desvalorização e de desqualificação dos professores, da escola e do processo educativo.

Na pesquisa, a análise dos dados do SAEB foi feita na perspectiva de que eles se constituam em importante meio de diagnóstico, a partir do qual se estabeleça uma comunicação entre a escola, os professores, os alunos, a sociedade e o Estado, como forma de regular a qualidade do processo e dos resultados.

A avaliação faz parte do contrato social da educação oferecida pelo Estado à sociedade. Nesse sentido, ela deve ser integrada ao conjunto das partes que compõem o processo educativo. Ela não deve ser algo prescrito, mas algo que deve ser construído por todos os envolvidos, ou seja, os indicadores avaliados devem ser definidos por todos, pois negando a participação, resta aos professores e demais profissionais das escolas prepararem os alunos para as provas padronizadas. Daí a necessidade de que o professor tenha a qualificação necessária para poder analisar, criticar e interpretar os dados.

Em caso contrário, os avaliadores podem enfraquecer a legitimidade dos indicadores, levando, por exemplo, a considerar o professor como culpado de um problema que tem uma determinação mais ampla. Além do que, achar um culpado para a ineficácia da escola é simplificar o problema e desresponsabilizar - Estado, evitando analisar adequadamente a formação e as condições de trabalho dos professores. Desse modo, as avaliações não podem promover a concorrência e a competição entre escolas, alunos e professores, na busca por uma classificação honrosa, pois desse modo a escola perde a sua função social que é a de promover uma educação de mesma qualidade para todos, tendo em vista contribuir para a emancipação dos sujeitos.

À guisa de conclusão, cabe ressaltar: a valorização e a profissionalização do magistério público não é uma questão somente da profissão, ela envolve um conceito de educação de qualidade mais amplo. A qualidade do ensino é prescrita na CF como um direito de todos e dever do Estado, portanto, dela deriva também o direito da população de contar com profissionais valorizados e profissionalizados. Concomitante à garantia do padrão de educação de qualidade como um direito de todos, concorre à garantia de qualidade dos fatores que determinam o mesmo, nesses se incluem os profissionais da educação. Assim, a contribuição da pesquisa depende de investigações futuras que avaliem o avanço, a superação ou a permanência dos problemas revelados em 2003, por meio das indicações aqui apresentadas, utilizando dados posteriores do Sistema Nacional de Educação Básica e estudos de caso que permitam aprofundar as análises aqui realizadas. 


\section{Referências Bibliográficas}

BIASI, S. V. O professor e qualidade de ensino: uma análise a partir dos resultados do SAEB na escola pública do PARANÁ. Dissertação de Mestrado. UFPR, 2009. Orientadora: Rose Meri Trojan.

BRASIL. Constituição da República Federativa do Brasil. Brasília: Senado Federal, 1988.

BRASIL. Lei n. ${ }^{\circ}$ 10.172, de 9 de janeiro de 2001. Aprova o Plano Nacional de Educação. Brasília: MEC, 2001.

BRASIL. Lei n. 9.394, de 20 de dezembro de 1996.

DUBET, F. (2004). O que é uma escola justa? Cadernos de Pesquisa, 34 (123).

SOARES, J. F. e MAROTTA L.. Desigualdades no Ensino Fundamental Brasileiro. V REUNIÃO ANUAL DA ABAVE.

MEC. Leia-me - SAEB 2003. INEP, 2006.

MEC. PDE: Plano de Desenvolvimento da Educação :Prova Brasil : ensino fundamental : matrizes de referência, tópicos e descritores. Brasília: MEC, SEB; Inep, 2008.

MEC/INEP. 2003. Microdados SAEB 2003. Mídia eletrônica. Brasília.

OLIVEIRA, R. P. de; ARAUJO, G. C. de. Qualidade do ensino: uma nova dimensão da luta pelo direito à educação. Revista Brasileira de Educação, Rio de Janeiro, n. ${ }^{\circ}$ 28, p. 5-23, abr. 2005.

PARO, V. H. Escritos sobre educação. São Paulo. Xamã, 2001. 